\title{
Effect of the Solvent Flow Rate on the Ionization Efficiency in Atmospheric Pressure Photoionization-Mass Spectrometry
}

\author{
Tiina J. Kauppila* and Andries P. Bruins \\ University Center for Pharmacy, University of Groningen, Groningen, The Netherlands
}

\author{
Risto Kostiainen* \\ Division of Pharmaceutical Chemistry, Faculty of Pharmacy, University of Helsinki, Helsinki, Finland
}

In the novel atmospheric pressure photoionization-mass spectrometry the ionization efficiency has been observed to decrease when the solvent flow rate is increased. The effect of the flow rate on the ionization efficiency was studied by comparing the behavior of two analytes, one of which is ionized through charge exchange, the other through proton transfer. Additional information about the ion loss mechanisms was obtained by comparing results obtained with two different APPI ion sources: a Sciex prototype and the Agilent/Syagen APPI source. In addition to the measurements done by using the mass analyzer, the total ion current in the ion source was obtained by measuring the currents of the ions arriving at curtain/end plate and orifice/capillary of the two mass spectrometers. The total ion current measurements showed a significant decrease at high solvent flow rates. Loss of dopant radical cations was thought to be the reason for the signal decrease of the analytes formed through charge exchange. Analytes formed through proton transfer were not as seriously affected by the high solvent flow rates, but some saturation of their signal was nevertheless observed. Loss of photons through absorption by solvent vapor is another mechanism that can be held responsible for a reduction of the total number of ions produced by the APPI source. (J Am Soc Mass Spectrom 2005, 16, 1399-1407) (C) 2005 American Society for Mass Spectrometry

A tmospheric pressure photoionization (APPI) has recently been introduced as a new ionization method for liquid chromatography-mass spectrometry (LC-MS) [1, 2]. Two distinct APPI apparatuses have been described by Robb et al. [1] and Syage et al. [2], which use the same operational principle. In both apparatuses, the liquid sample solution is first evaporated by nebulization and high-temperature desolvation, after which the gaseous analytes are ionized through photoionization and gas-phase reactions. The major difference between the two ion sources is in their construction: in the ion source introduced by Robb et al. [1] the ionization takes place inside a narrow $7 \mathrm{~mm}$ i.d. metal tube (Figure 1), whereas Syage's ion source [2] uses a more open space for ionization (Figure 2). In addition, the ion source by Robb et al. requires the use of a dopant.

The ionization in APPI is initiated by $10 \mathrm{eV}$ photons

Published online June 24, 2005

Address reprint requests to Dr. A. P. Bruins, Center of Pharmacy, University of Groningen, A. Deusinglaan 1, 9713 AV Groningen, The Netherlands. E-mail: a.p.bruins@rug.nl

* Also at the Viikki Drug Discovery Technology Center, Faculty of Pharmacy, University of Helsinki, P.O. Box 56, FIN-00014 Helsinki, Finland emitted by a krypton discharge lamp. The photons can ionize molecules that possess ionization energies (IEs) below $10 \mathrm{eV}$. This includes most analytes, but leaves out solvents generally used in LC, such as methanol, acetonitrile, and water, as well as the gases used in the nebulization or otherwise present in the atmospheric pressure ion source. In direct photoionization, i.e., without dopant, the analyte forms a radical cation, $\mathrm{M}^{+}$. (Scheme 1, Reaction 1), which can further react with other gas-phase species by charge exchange or hydrogen abstraction (Scheme 1, Reactions 2 and 3) [2]. Dopant assisted APPI uses a readily ionizable compound (e.g., toluene) to enhance the ionization of the analytes. The ionization is initiated by photoionization of the dopant and formation of a dopant radical cation (Scheme 1, Reaction 4) [1, 3, 4]. The dopant radical cation can ionize the analyte directly by charge exchange if the ionization energy of the analyte is lower than that of the dopant (Scheme 1, Reaction 7). Alternatively, the dopant radical cation can further ionize the solvent molecules by proton transfer if the proton affinity (PA) of a solvent cluster is higher than that of the deprotonated dopant radical cation (Scheme 1, Reaction 5). Protonated solvent clusters can in turn 


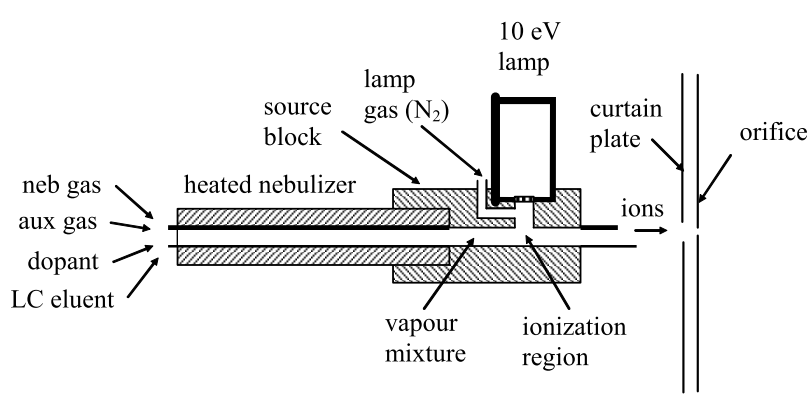

Figure 1. Schematic of the Sciex prototype source.

donate a proton to the analyte, in case the PA of the analyte is higher than that of the solvent cluster (Scheme 1, Reaction 6). In this case, APPI is effectively "photon induced chemical ionization." In the presence of methanol and acetonitrile, transfer of a proton from the dopant ions of toluene to a solvent cluster is such an effective process that the APPI spectrum is almost devoid of dopant ions and analyte ionization is the result of proton transfer from protonated solvent clusters, while charge-transfer under such conditions is very ineffective. Compounds that are ionized via proton transfer usually possess high proton affinities (PAs) and could therefore also be ionized using ESI or APCI. However, as the charge exchange is dependent on the ionization energy of the compound, it allows the ionization of low PA compounds, which usually are nonpolar molecules, and therefore, difficult to ionize by ESI or APCI.

In negative ion APPI the ionization process is started by the release of an electron in the photoionization of the dopant (Scheme 1, Reaction 4) [5] or from the ion source metal surfaces attributable to the radiation with the photons [6]. These low-energy electrons may be captured by species that possess positive electron affinity, such as analytes, solvents, or gases. Thus formed negative molecular ions can react further via proton transfer, charge exchange, or oxidation. The formation of negative ions in APPI has recently been discussed in two publications and is not discussed further here $[5,6]$.

APPI has broadened the group of compounds that can be analyzed by atmospheric pressure ionizationmass spectrometry (API-MS) techniques and has thus far been applied to the analysis of flavonoids [7], steroids [8], drugs and their metabolites [9-13], naphthalenes [3, 5, 14], aromatic imines and amines [15], organic fluorochemicals [16], mycotoxins [16], fungicides [17], furocumarins [18], antibiotics [19], and peptides [20]. Generally, APPI has shown equal or even better sensitivity than APCI [1, 5, 7, 21], but has, however, a defect that may limit its applicability in liquid chromatography-mass spectrometry (LC-MS): the sensitivity in APPI has been observed to decrease when the solvent flow rate is increased [10, 21-23]. In most applications done this far the solvent flow rate used has been $200 \mu \mathrm{l} / \mathrm{min}[1,3,5,7,8]$, whereas with APCI flow rates up to $2 \mathrm{ml} / \mathrm{min}$ can be used routinely [24].
Possible reasons for the signal decrease in APPI include insufficient amount or loss of photons, neutralization of ions (including the dopant) in recombination reactions with electrons or other neutral or ionic species present in the ion source, as well as neutralization of ions to the source walls (Scheme 2). The aim of this work was to study the interdependence between flow rate and ionization efficiency of APPI. This is done by analyzing two compounds, which are ionized through two different ionization mechanisms: charge exchange and proton transfer. The measurements are done by changing the flow rates of the solvent, the dopant, and the analyte, and monitoring the effect of the flow rate on the analyte signal and the total ion current in the ion source. Two different APPI sources: the PE Sciex prototype and the Agilent/Syagen APPI source are used in the experiments, which enables the comparison of different constructional effects, such as volume of the ionization region as well as possible effects caused by the dopant.

\section{Experimental}

\section{Reagents}

Acridine ( $\mathrm{HCl}$ salt) and 2-ethylnaphthalene were purchased from Sigma-Aldrich (Steinheim, Germany). Acetonitrile was purchased from Merck KGaA (Darmstadt, Germany), chloroform from Rathburn (Walkerburn, Scotland), and toluene from J. T. Baker (Phillipsburg, $\mathrm{NJ})$. All solvents were of chromatographic grade.

\section{Sample Preparation}

Stock solutions of $10^{-2} \mathrm{M}$ acridine and 2-ethylnaphthalene were prepared in acetonitrile and chloroform,

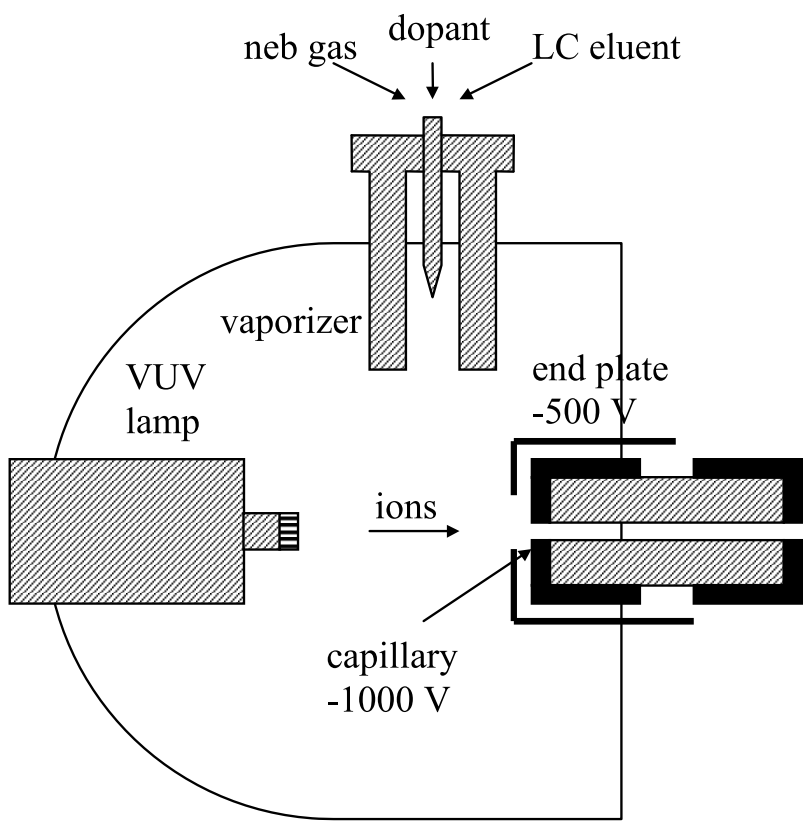

Figure 2. Schematic of the Agilent/Syagen APPI source. 


\begin{tabular}{|c|c|c|c|}
\hline $\mathrm{M}$ (analyte) $+10 \mathrm{eV}$ photons & $\rightarrow$ & $\mathrm{M}^{+\cdot}+\mathrm{e}^{-}$ & if IE (M) $<10 \mathrm{eV}$ \\
\hline $\mathrm{M}^{+\cdot}+\mathrm{X}$ & $\rightarrow$ & $\mathrm{M}+\mathrm{X}^{+*}$ & if $\mathrm{IE}(\mathrm{X})<\mathrm{IE}(\mathrm{M})$ \\
\hline $\mathrm{M}^{+\cdot}+\mathrm{S}$ (solvent) & $\rightarrow$ & $\mathrm{MH}^{+}+[\mathrm{S}-\mathrm{H}]^{-}$ & \\
\hline $\mathrm{D}$ (dopant) $+10 \mathrm{eV}$ photons & $\rightarrow$ & $\mathrm{D}^{+\cdot}+\mathrm{e}^{-}$ & \\
\hline $\mathrm{D}^{+\cdot}+\mathrm{n} \mathrm{S}$ (solvent or impurity) & $\rightarrow$ & {$[D-H]^{-}+\mathrm{S}_{n} \mathrm{H}^{+}$,} & if $P A\left(S_{n}\right)>P A\left([D-H]^{\prime}\right)$ \\
\hline $\mathrm{S}_{\mathrm{n}} \mathrm{H}^{+}+\mathrm{M}^{+}$ & $\rightarrow$ & $\mathrm{MH}^{+}+\mathrm{n} \mathrm{S}$ & if $P A(M)>P A\left(S_{n}\right)$ \\
\hline $\mathrm{D}^{+\cdot}+\mathrm{M}^{+\cdot}$ & $\rightarrow$ & $\mathrm{M}^{+\cdot}+\mathrm{D}$ & if IE $\left(M^{+\cdot}\right)<I E(D)$ \\
\hline $\mathrm{D}^{+\cdot}+\mathrm{S}$ & $\rightarrow$ & no proton transfer, & if $P A(S)<P A\left([D-H]^{\prime}\right)$ \\
\hline $\mathrm{D}^{+\cdot}+\mathrm{M}$ & $\rightarrow$ & {$[\mathrm{D}-\mathrm{H}]^{-}+\mathrm{MH}^{+}$} & if $P A(M)>P A\left([D-H]^{\circ}\right)$ \\
\hline
\end{tabular}

Scheme 1. Ion formation mechanisms in positive ion APPI.

respectively, and diluted to a final concentration of $10^{-5} \mathrm{M}$.

\section{Instrumentation}

The solvents were delivered by using an Applied Biosystems 140 B Solvent Delivery System (Applied Biosystems, Foster City, CA) at flow rates of $50-1000$ $\mu \mathrm{l} / \mathrm{min}$. The $10^{-5} \mathrm{M}$ samples were delivered as a continuous stream by using a micro-syringe pump (kdScientific, Boston, MA) and connected to the solvent flow by means of a T-piece. Another micro-syringe pump (Harvard Apparatus, South Natick, MA) was used to deliver the HPLC-grade toluene as a dopant at flow rates of $5-100 \mu \mathrm{l} / \mathrm{min}$. The mass spectrometers used were a PE Sciex API 365 triple quadrupole mass spectrometer (Sciex, Concord, Ontario, Canada) and an Agilent 1100 Series LC/MSD Trap SL (Agilent Technologies, Waldbronn, Germany). The API 365 mass spectrometer used a prototype APPI source (Machine Shop, University of Groningen, Netherlands), with a $10 \mathrm{eV}$ Model PKS 100 krypton discharge lamp (Cathodeon Ltd., Cambridge, England). High purity nitrogen $(<5$ ppm $\mathrm{H}_{2} \mathrm{O}$ and $<3$ ppm $\mathrm{O}_{2}$ ) was used as nebulizer, auxiliary, curtain, and lamp gases. The operational parameters were optimized for each analyte. Mass spectra were acquired over the scan range $m / z 30-500$ using step size of 0.1 and dwell time of $0.3 \mathrm{~ms}$.

The Agilent ion trap used an Agilent G1971A APPI source, developed by Syagen (Agilent technologies, Palo Alto, CA). Nitrogen was used as nebulizer and drying gases. The drying gas temperature was $325^{\circ} \mathrm{C}$, drying gas flow $5 \mathrm{l} / \mathrm{min}$ and nebulizer gas pressure 60 psi. The capillary voltage was $1000 \mathrm{~V}$, skimmer voltage and capillary exit voltage 30 and $120 \mathrm{~V}$, respectively. The spectra were acquired over the scan range $\mathrm{m} / \mathrm{z}$ $30-500$ by using averages of 10 .

\section{Curtain Plate and Orifice Measurements}

The currents at the PE Sciex API 365 curtain plate and orifice were measured by using a home made floating electrometer system. The output of the electrometer was continuously recorded by using a MacLab system with Chart 3.5.7 software (AD Instruments, Castle Hill, NSW, Australia)

\section{Results and Discussion}

To investigate the effect of the solvent flow rate on the ionization efficiency, chloroform and acetonitrile were chosen as the solvents, and acridine and 2-ethylnaphthalene were chosen as model compounds. Acridine and 2-ethylnaphthalene both possess low ionization energies (IEs) and can therefore be ionized via direct photoionization ${ }^{\circ}$ or $^{\circ}$ charge $^{\circ}$ exchange $^{\circ}\left(\right.$ Scheme $^{\circ} \mathbf{1}^{\circ}{ }^{\circ}$ Reactions 1 and 7).

The effect of the flow rate on charge exchange or direct photoionization was studied with 2-ethylnaphthalene by using chloroform as the solvent. Because of the low PA of chloroform, proton transfer between the dopant radical cation and the solvent cannot take place (Scheme 1, ${ }^{\circ}$ Reaction ${ }^{\circ}$ ), ${ }^{\circ}$ and ${ }^{\circ}$ the ${ }^{\circ}$ only $^{\circ}$ possibleionization routes are direct photoionization or charge exchange (Scheme ${ }^{\circ} 1^{\circ}$ Reactions ${ }^{\circ} 1^{\circ}$ and $^{\circ} 7$ ).

Acridine also possesses high proton affinity (PA), and is therefore usually ionized through proton transfer (Scheme 1, ${ }^{\circ}$ Reaction ${ }^{\circ}$ ). ${ }^{\text {T Therefore, }}$, the ${ }^{\circ}$ effect ${ }^{\circ}$ of ${ }^{\circ}$ the ${ }^{\circ}$ flow

Loss of photons:

Collisions to surfaces

Absorption by dopant, solvent and sample molecules without ion formation

Loss of positive ions (including dopant), with reduction of the total ion current:

Recombination with a negative ion: $\mathrm{M}^{+\cdot}+\mathrm{A}^{-} \rightarrow \mathrm{MA}$

Electron capture: $\mathrm{M}^{+\cdot}+\mathrm{e}^{-} \rightarrow \mathrm{M}$

Charge exchange with a negative ion: $\mathrm{M}^{+\cdot}+\mathrm{A}^{-} \rightarrow \mathrm{M}+\mathrm{A}$

Discharge against source walls: $\rightarrow$ neutralization

Loss of positive ions (including dopant), without reduction of the total ion current:

Charge exchange with a neutral: $\mathrm{M}^{+\cdot}+\mathrm{A} \rightarrow \mathrm{M}+\mathrm{A}^{+}$

Proton transfer with a neutral: $\mathrm{MH}^{+}+\mathrm{A} \rightarrow \mathrm{M}+\mathrm{AH}^{+}$

Scheme 2. Possible loss mechanisms for photons and ions in APPI. 
Table 1. Energetics of the solvents and compounds studied [26]

\begin{tabular}{lcc}
\hline & $\mathrm{IE}(\mathrm{eV})^{\mathrm{a}}$ & $\mathrm{PA}(\mathrm{kJ} / \mathrm{mol})^{\mathrm{a}}$ \\
\hline \hline Benzyl radical & 7.20 & 831.4 \\
Toluene & 8.83 & 784.0 \\
Acetonitrile & 12.20 & 779.2 \\
Chloroform & 11.37 & - \\
Acridine & 7.80 & 972.6 \\
2-ethylnaphthalene & 7.95 & $835.9^{\mathrm{b}}$ \\
2-methylnaphthalene & & 831.9 \\
\hline
\end{tabular}

${ }^{\mathrm{a}} \mathrm{IE}$, ionization energy; $\mathrm{PA}$, proton affinity.

bThe PA of 2-ethylnaphthalene was estimated from the PA of ethylbenzene; the substituted naphthalene ring was estimated to have an approx. $48 \mathrm{~kJ} / \mathrm{mol}$ higher PA than the substituted benzene ring. This was calculated from the PAs of toluene $(784.0 \mathrm{~kJ} / \mathrm{mol})$ and 2-methylnaphthalene $(831.9 \mathrm{~kJ} / \mathrm{mol})$.

rate on the proton transfer reaction was studied with acridine by using acetonitrile as the solvent. In acetoni-

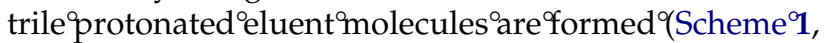
Reaction 5) and acridine is efficiently protonated because $^{\circ}$ of $^{\circ}$ its $^{\circ}$ high $^{\circ} \mathrm{PA}^{\circ}\left(\right.$ Scheme $^{\circ} 1^{\circ}$ Reaction $\left.^{\circ} 6\right) .^{\circ} \operatorname{In}^{\circ}$ the absence of proton donors the $\mathrm{MH}^{+}$ion of acridine may be formed by transfer of a hydrogen atom to the $\mathrm{M}^{+\cdot}$ ion of $^{\circ}$ acridine $^{\circ}\left(\text { Scheme }^{\circ} 1^{\circ} \text { Reaction }^{\circ} 3\right)^{\circ}[25] .{ }^{\circ}$ This $^{\circ}$ latter mechanism is effective when acridine is ionized by direct photoionization, without the use of toluene as the dopant in the Agilent APPI source, see below.

Thermodynamical data for the studied compounds and $^{\circ}$ solvents ${ }^{\circ} \operatorname{are}^{\circ}$ shown $^{\circ}$ in $^{\circ}$ Table $^{\circ} 1 .^{\circ}$ Two $^{\circ}$ ion $^{\circ}$ sources, Sciex prototype source and Agilent/Syagen APPI source were used in the study. In the Sciex prototype source, the ionization takes place inside a narrow $7 \mathrm{~mm}$ i.d. ${ }^{\circ}$ metal $^{\circ}$ tube $^{\circ}$ (Figure $\left.{ }^{\circ} 1\right)^{\circ}$, whereas $^{\circ}$ in $^{\circ}$ the ${ }^{\circ}$ Agilent $/$ Syagen $^{\circ}$ APPI $^{\circ}$ source $^{\circ}\left(\text { Figure }^{\circ} 2\right)^{\circ}$ the ${ }^{\circ}$ ionization ${ }^{\circ}$ takes place in an open ionization region. Dopant was used in all the experiments carried out with the Sciex source, since without dopant the compounds studied were not ionized at all. However, the Agilent APPI source provides significantionization also ${ }^{\circ}$ without ${ }^{\circ}$ dopant [2], and therefore, experiments with Agilent source were carried out with and without dopant.

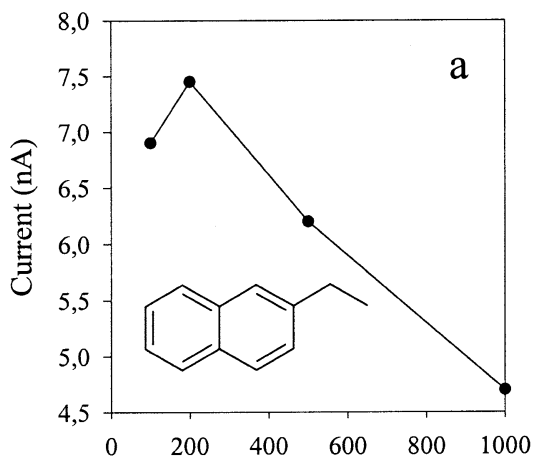

Sample solution flow rate $(\mu 1 / \mathrm{min})$
The sample, solvent and dopant flow rates were adjusted so that the relative proportions of the dopant, analyte, and solvent were constant at all solvent flow rates (dopant flow rate was $10 \%$ of the solvent flow rate). The solvent flow rates used with the prototype Sciex source were between 100-1000 $\mu \mathrm{l} / \mathrm{min}$ and with the Agilent source between 50-1000 $\mu \mathrm{l} / \mathrm{min}$. The ionization efficiency below the lowest flow rates used in these experiments was found to be inadequate for efficient ionization due to too low mass flow of the dopant.

In addition to the measurements done with the mass analyzers, the ion currents at the curtain plate and orifice ${ }^{\circ}$ of ${ }^{\circ}$ the $^{\circ} \mathrm{Sciex}^{\circ} \mathrm{MS}^{\circ}\left(\text { Figure }^{\circ} 1\right)^{\circ}$ and $^{\circ}$ at $^{\circ}$ the $^{\circ}$ end $^{\circ}$ plate and $^{\circ}$ capillary $^{\circ}$ of $^{\circ}$ the ${ }^{\circ}$ Agilent $^{\circ}$ MS $^{\circ}\left(\text { Figure }^{\circ} 2\right)^{\circ}$ were $^{\circ}$ also recorded. The currents at the curtain plate and end plate indicate the amount of all the ions inside the ion sources, whereas the currents at the orifice and capillary indicate the amount of ions that enter the mass spectrometer. These measurements give a more truthful description of the amount of ions in the ion source than the reconstructed total ion current measured with the mass analyzer, which can be affected by poor transportation of ions into the mass analyzer and by discrimination against low mass ions.

\section{Effect of the Solvent Flow Rate on Total Ion Current Output}

The results from the flow rate experiments are presented ${ }^{\circ}{ }^{\circ}{ }^{\circ}$ Figures $^{\circ} 3,{ }^{\circ} 4,{ }^{\circ},{ }^{\circ} 6,{ }^{\circ}$ and ${ }^{\circ} 7 .{ }^{\circ}$ The ${ }^{\circ}$ curtain ${ }^{\circ}$ plate ${ }^{\circ}$ and orifice currents (Sciex prototype source) and the end plate and capillary currents (Agilent/Syagen) were observed to decrease as the flow rate was increased in all the $^{\circ}$ experiments ${ }^{\circ}$ where ${ }^{\circ}$ dopant $^{\circ}$ was ${ }^{\circ}$ present $t^{\circ}$ (Figures $3 a,{ }^{\circ} 4 a,{ }^{\circ} 6 a,{ }^{\circ}$ and ${ }^{\circ} 7 a ;{ }^{\circ}$ orifice ${ }^{\circ}$ and ${ }^{\circ}$ capillary $^{\circ}$ currents $^{\circ}$ not shown). The decrease at the higher flow rates was stronger in the Agilent/Syagen source than in the Sciex prototype source. An especially high dependence of the measured currents on the amount of dopant radical cations in the system was observed, as indicated by the

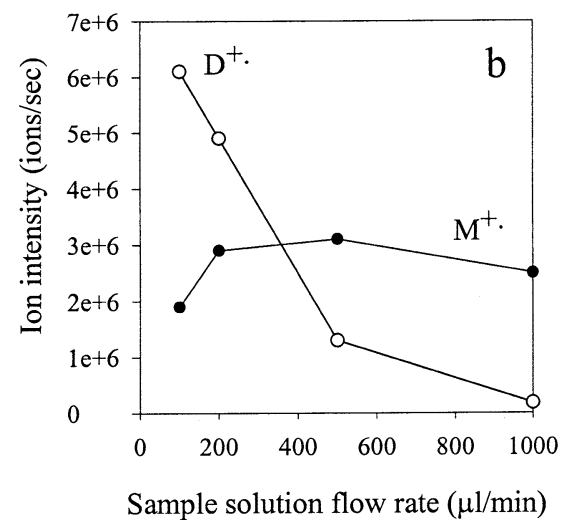

Figure 3. 2-Ethylnaphthalene in chloroform by using the Sciex prototype source. (a) Curtain plate current; (b) intensities of $\mathrm{M}^{+}$of 2-ethylnaphthalene and $\mathrm{D}^{+\cdot}$ of toluene. Chloroform flow rate $100-1000 \mu \mathrm{l} / \mathrm{min}$, dopant flow rate 10-100 $\mu \mathrm{l} / \mathrm{min}$ and 2-ethylnaphthalene concentration $200 \mathrm{nM}$. 


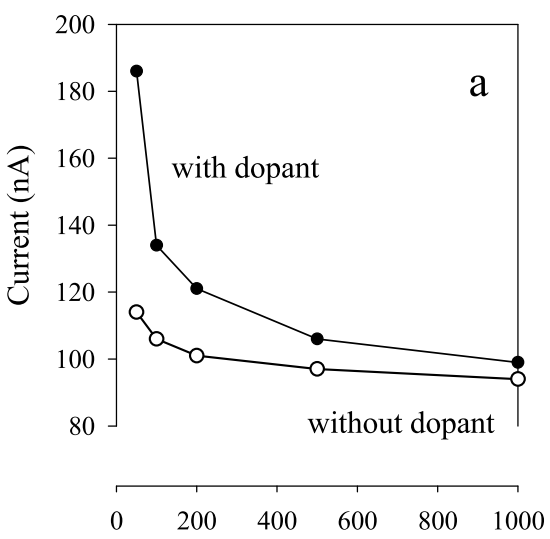

Sample solution flow rate $(\mu 1 / \mathrm{min})$

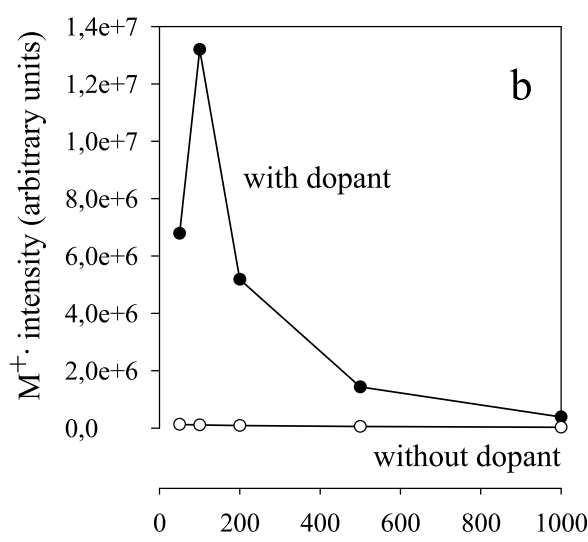

Sample solution flow rate $(\mu 1 / \mathrm{min})$

Figure 4. 2-Ethylnaphthalene in chloroform by using the Agilent/Syagen APPI source. (a) End plate current; (b) intensity of $\mathrm{M}^{+}$. Chloroform flow rate $50-1000 \mu \mathrm{l} / \mathrm{min}$, dopant flow rate 5-100 or 0 $\mu \mathrm{l} / \mathrm{min}$ and 2-ethylnaphthalene concentration $1.4 \mu \mathrm{M}$.

simultaneous decrease in the signal of the dopant radical ${ }^{\circ}$ cation $^{\circ}$ and the $^{\circ}$ currents $^{\circ}$ (Figures $3 a, 3 b, 4 a$, and 5 ) and by the 2 .olliseistadiogn, that the currents were in minimum in the measurements done without the dopant ${ }^{\circ}$ (Figures $4 \mathrm{a}^{\circ}$ and $\% \mathrm{a}$ ). The ${ }^{\circ}$ severe loss ${ }^{\circ}$ of reactantions in the system is assumed to have a strong effect also on the ionization efficiency of the analytes.

\section{Effect of the Solvent Flow Rate on Charge Exchange}

The experiments made with the Sciex prototype source using chloroform as the solvent and toluene as the dopant showed that the absolute abundance of $\mathrm{M}^{+}$of 2-ethylnaphthalene formed by charge exchange reaction increased sharply at first, as the solvent flow rate and the analyte mass flow were increased. At solvent flows above $200 \mu \mathrm{l} / \mathrm{min}$ the $\mathrm{M}^{+}$signal started to saturate and finally, ${ }^{\circ}$ after $500^{\circ} \mu \mathrm{l} / \mathrm{min}$, ${ }^{\circ}$ decreased (Figure $3 b) .^{\circ}$ When ${ }^{\circ}$ the ${ }^{\circ}$ Agilent $/$ Syagen $^{\circ}$ APPI $^{\circ}$ source $^{\circ}$ was $^{\circ}$ used, the abundance of $\mathrm{M}^{+}$of 2-ethylnaphthalene decreased abruptly ${ }^{\circ}{ }^{\circ}{ }^{\circ}$ solvent ${ }^{\circ}$ flow ${ }^{\circ}$ rates ${ }^{\circ} 100-1000^{\circ} \mu \mathrm{l} / \mathrm{min}^{\circ}$ (Figure $4 b) .{ }^{\circ}$ The ${ }^{\circ}$ decrease ${ }^{\circ}$ of ${ }^{\circ}$ the ${ }^{\circ} \mathrm{M}^{+}{ }^{\circ}$ signals $^{\circ}$ was $^{\circ}$ thought ${ }^{\circ}$ to ${ }^{\circ}$ be caused by the gradual depletion of the toluene radical cation, as implied by the fading of the $\mathrm{M}^{+\cdot}$ of toluene from $^{\circ}$ the $^{\circ}$ spectrum $^{\circ}\left(\right.$ Figures $^{\circ} 3 \mathrm{~b}^{\circ}$ and $\left.^{\circ} 5\right) .^{\circ}$ As $^{\circ}$ the ${ }^{\circ}$ toluene radical cation is depleted, the charge exchange between the ${ }^{\circ}$ toluene $^{\circ}$ radical $^{\circ}$ cation $^{\circ}$ and $^{\circ}$ the $^{\circ}$ analyte $^{\circ}\left(\right.$ Scheme $^{\circ} \mathbf{1}$, Reaction 7) becomes inhibited, which results in decrease of the analyte signal. With the Agilent/Syagen source the ionization of 2-ethylnaphthalene could not be achieved without the dopant at any solvent flow rate, and the total ${ }^{\circ}$ amount $^{\circ}$ of $^{\circ}$ ions ${ }^{\circ}$ was $^{\circ}$ minimal ${ }^{\circ}$ as $^{\circ}$ shown by the ${ }^{\circ}{ }^{\circ}{ }^{\circ}$ end $^{\circ}$ plate $^{\circ}$ current $^{\circ}\left(\right.$ Figure $\left.^{\circ} 4 \mathrm{a}\right)$. This confirms that the yield of $\mathrm{M}^{+}$ions is highly dependent on the amount of dopant radical cations in the system, which implies that charge exchange with the toluene radical cation is the main route for the formation of analyte radical cations, instead of direct photoionization, at least under the conditions of our ${ }^{\circ}$ experiments. ${ }^{\circ}$
The ${ }^{\circ}$ possible ${ }^{\circ}$ neutralization reactions for the radical Sahiome ${ }^{\circ} f^{\circ}$ dopant $^{\circ}$ and $^{\circ}$ sample $^{\circ}$ are $^{\circ}$ presented $^{\circ}$ in decrease ${ }^{\circ}$ f $^{\circ}$ curtain $^{\circ}$ and ${ }^{\circ}$ end $^{\circ}$ plate currents suggests that the neutralization takes place by reactions that produce neutral species; i.e., by recombination with a negative ion, electron capture, charge exchange with a negative ion, or by discharge against source $^{\circ}$ walls (Scheme ${ }^{\circ}$, Reactions 3-6). This is possible with APPI, since positive and negative ions can be present simultaneously. The role $^{\circ}$ of $^{\circ}$ charge $^{\circ}$ exchange $^{\circ}$ and ${ }^{\circ}$ proton transfer ${ }^{\circ}$ reactions ${ }^{\circ}\left(\right.$ Scheme $^{2},{ }^{\circ}$ Reactions ${ }^{\circ} 7^{\circ}$ and $\left.{ }^{\circ} 8\right)$ in the neutralization of dopant radical cations cannot be ruled out either. With chloroform as the solvent, proton transfer with the solvent is unlikely, but solvent impurities may be involved in the loss of dopant and analyte ions. This latter aspect is indeed observed in the spectra of ethylnaphthalene, where the relative abundance of ions at $m / z 99$ and 139 increases with increasing solution flow rate. The identity of the compounds that correspond with the ions at $m / z 99$ and 139 is unknown. The compounds may be either impurities, or may be stabilizers present in chloroform to prevent the formation of phosgene.

\section{Effect of the Solvent Flow Rate on Proton Transfer Reaction}

The effect of solvent flow rate on the proton transfer reaction was studied with acridine by using acetonitrile as a solvent, which produced a very abundant $\mathrm{MH}^{+}$ ion. The abundance of $\mathrm{MH}^{+}$leveled off to a minor extent with the Sciex prototype source. With the Agilent/Syagen source loss of ionization efficiency was nearly ${ }^{\circ}$ absent ${ }^{\circ}$ when ${ }^{\circ}$ dopant $^{\circ}$ was $^{\circ}$ used $^{\circ}$ (Figures ${ }^{\circ} 6^{\circ}$ and 7 ). With the Agilent/Syagen source the signal saturation was stronger when direct photoionization was employed without the use of a dopant. However, in all cases the abundance of $\mathrm{MH}^{+}$of acridine increased when the flow rate was increased, unlike the abundance of $\mathrm{M}^{+}$of 2-ethylnaphthalene, which strongly decreased 


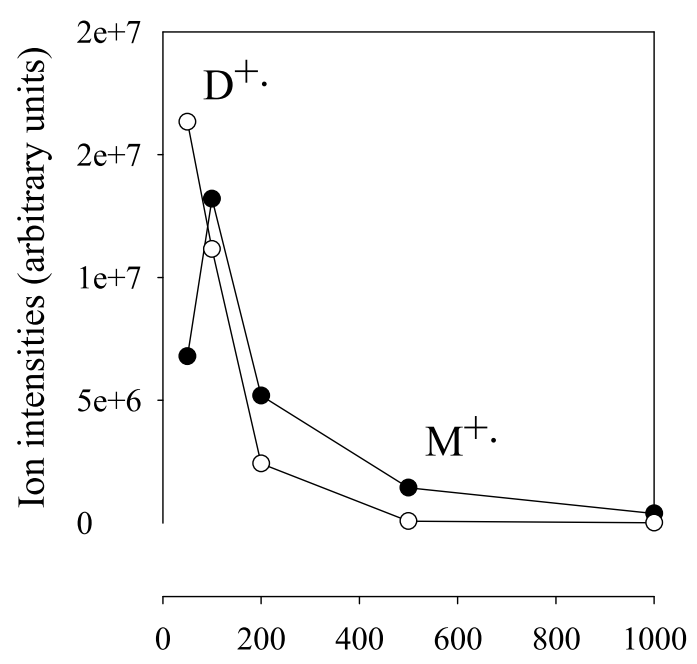

Sample solution flow rate $(\mu 1 / \mathrm{min})$

Figure 5. 2-Ethylnaphthalene by using the Agilent/Syagen APPI source. Intensities of $\mathrm{M}^{+}$of 2-ethylnaphthalene and $\mathrm{D}^{+}$of toluene. Chloroform flow rate 50-1000 $\mu \mathrm{l} / \mathrm{min}$, dopant flow rate 5-100 $\mu \mathrm{l} / \mathrm{min}$ and 2-ethylnaphthalene concentration $1.4 \mu \mathrm{M}$.

at ${ }^{\circ}$ higher ${ }^{\circ} \mathrm{flow}^{\circ}{ }^{\circ}$ ates $^{\circ}\left(\right.$ Figures $^{\circ} 3,{ }^{\circ},{ }^{\circ}$ and $\left.^{\circ} 5\right)$. ${ }^{\circ}$ This ${ }^{\circ}$ indicates that the efficiency of sample ionization by proton transfer is less dependent on the flow rate than the efficiency of sample ionization by charge exchange. The charge exchange reaction discussed in the section above is very dependent on the amount of dopant radical cations in the system and the efficiency of ionization of a sample is clearly decreased when the amount of dopant radical cations ${ }^{\circ}$ is $^{\circ}$ decreased $^{\circ}\left(\right.$ Figures $^{\circ} 3,{ }^{\circ},{ }^{\circ}$ and $\left.^{\circ} 5\right)$. ${ }^{\circ}$ Some ${ }^{\circ}$ saturation of the $\mathrm{MH}^{+}$signal of acridine could nevertheless be observed at higher flow rates. This may be caused by the neutralization of the initially formed dopant radical cations at higher flow rates, which causes a decrease in the amount of proton donating species, so that an insufficient amount of reactant ions is available for the efficient protonation of the increased acridine mass flow. This is supported by the observation that the signals of protonated acetonitrile $(\mathrm{m} / \mathrm{z} 42)$ and protonated acetonitrile clusters $(\mathrm{m} / \mathrm{z} 60$ and 83$)$ also decreased at higher flow rate.

In a discussion of the signal level of $\mathrm{MH}^{+}$ions of acridine in the absence of a dopant, two mechanisms of ion formation have to be considered: direct photoionization ${ }^{\circ}$ of $^{\circ}$ acridine ${ }^{\circ}\left(\text { Scheme }^{\circ}{ }^{\circ},{ }^{\circ} \text { Reaction }{ }^{\circ} 1\right)^{\circ}$ followed ${ }^{\circ}$ by hydrogen ${ }^{\circ}$ atom $^{\circ}$ abstraction ${ }^{\circ} s^{\circ}$ proposed $^{\circ}$ by $^{\circ}$ Syage $^{\circ}[25]$, and also, photon-induced isomerization and ionization of acetonitrile followed by proton transfer to acridine as proposed $^{\circ}$ by $^{\circ}$ Traldi $^{\circ}$ and ${ }^{\circ}$ coworkers ${ }^{\circ}[18] . .^{\circ}$ The $^{\circ}$ more intense signal of $\mathrm{MH}^{+}$of acridine with dopant than without $^{\circ}$ the ${ }^{\circ} \operatorname{dopant}^{\circ}\left(\text { Figure }^{\circ} 7\right)^{\circ}$ also $^{\circ}$ indicates ${ }^{\circ}$ that ${ }^{\circ}$ the amount of proton donating species is higher when the dopant is used and may explain the more significant saturation of the $\mathrm{MH}^{+}$signal without the dopant than

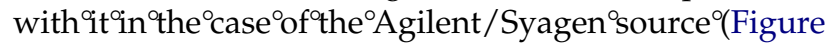
7). ${ }^{\circ}$ However, ${ }^{\circ}$ it ${ }^{\circ} s^{\circ}{ }^{\circ}$ also ${ }^{\circ}$ possible ${ }^{\circ}$ that ${ }^{\circ}$ other ${ }^{\circ}$ factors ${ }^{\circ}$ cause the saturation of the $\mathrm{MH}^{+}$signal of acridine at higher flow rates. First, the absolute amount of solvent impurities increases at higher flow rate, and species of higher PAs possibly start to compete with the analytes and thus ${ }^{\circ}$ decrease ${ }^{\circ}$ their ${ }^{\circ}$ protonation ${ }^{\circ}\left(S_{c h e m e}{ }^{\circ}\right.$, ${ }^{\circ}$ Reaction $\left.{ }^{\circ} 8\right)$. Second, the signal loss may also result from recombination of analyte ions with ions of opposite polarity $\left(\text { Scheme }^{\circ}{ }^{2},{ }^{\circ} \text { Reaction }^{\circ} 3\right)^{\circ}$ and $^{\circ}$ with $^{\circ}$ electrons ${ }^{\circ}\left(\right.$ Scheme $^{\circ} \mathbf{2}$, Reaction 4). Nevertheless, we feel it is difficult to rationalize why ion-ion and ion-electron recombination reactions should be promoted by an increasing amount of solvent vapor in the ion source.

Third, another possible reason for ion loss is discharge ${ }^{\circ}$ of ${ }^{\circ}$ ions ${ }^{\circ}$ to $^{\circ}$ ion $^{\circ}$ source $^{\circ}$ walls $^{\circ}\left(\right.$ Scheme $^{\circ}{ }^{\circ},{ }^{\circ}$ Reaction 6). This would be expected to be more pronounced with the Sciex prototype source, which uses a small ionization volume inside a metal tube, unlike the Agilent/ Syagen APPI source with a more open ionization area (Figures ${ }^{\circ} 1^{\circ}$ and ${ }^{\circ} 2$ )..$^{\circ}$ This ${ }^{\circ}$ hypothesis ${ }^{\circ}$ is ${ }^{\circ}$ supported ${ }^{\circ}$ by ${ }^{\circ}$ the observation that the $\mathrm{MH}^{+}$signals saturated more with the Sciex source than with the Agilent/Syagen APPI source $^{\circ}\left(\right.$ Figures $^{\circ} 6 b^{\circ}$ and $^{\circ} 7 \mathrm{~b}$ )..$^{\circ}$ It $^{\circ}$ is ${ }^{\circ}$ worth ${ }^{\circ}$ noting ${ }^{\circ}$ that

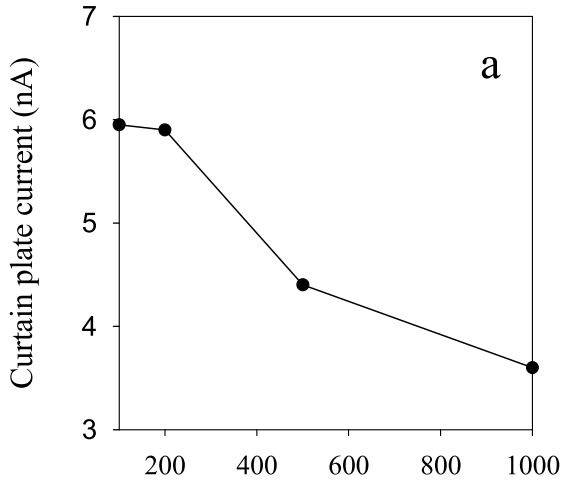

Sample solution flow rate $(\mu 1 / \mathrm{min})$

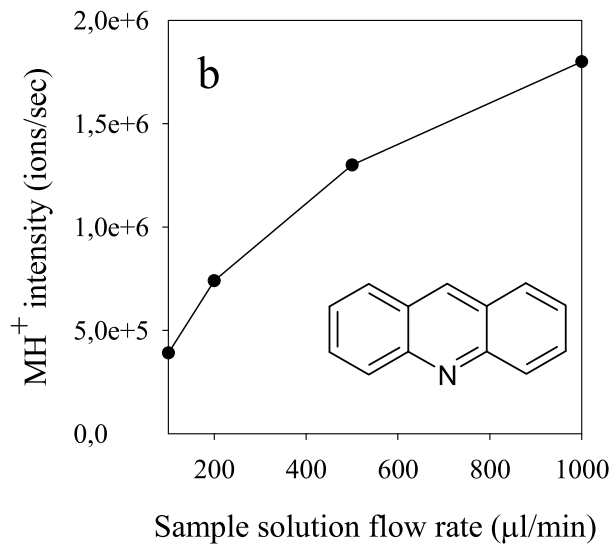

Sample solution flow rate $(\mu 1 / \mathrm{min})$

Figure 6. Acridine in acetonitrile by using the Sciex prototype source. (a) Curtain plate current; (b) intensity of the ${ }^{13} \mathrm{C}$ isotope peak of $\mathrm{MH}^{+}$at $m / z 181$. Acetonitrile flow rate $100-1000 \mu \mathrm{l} / \mathrm{min}$, dopant flow rate $10-100 \mu \mathrm{l} / \mathrm{min}$ and acridine concentration $200 \mathrm{nM}$ 


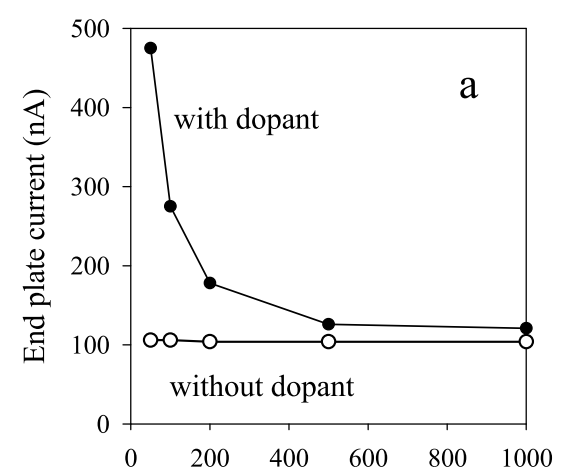

Sample solution flow rate $(\mu \mathrm{l} / \mathrm{min})$

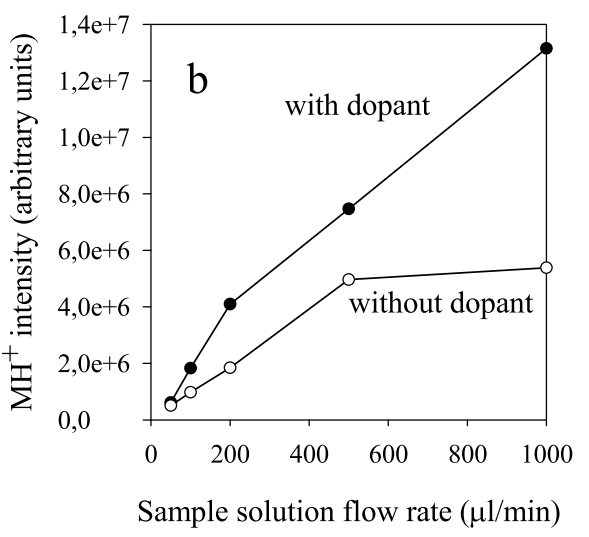

Figure 7. Acridine in acetonitrile by using the Agilent/Syagen APPI source. (a) End plate current; (b) intensity of $\mathrm{MH}^{+}$. Acetonitrile flow rate $50-1000 \mu \mathrm{l} / \mathrm{min}$, dopant flow rate 5-100 or $0 \mu \mathrm{l} / \mathrm{min}$ and acridine concentration $200 \mathrm{nM}$.

saturation of $m / z 180\left(\mathrm{MH}^{+}\right.$of acridine) is in part attributable to the saturation of the ion counting detector. Therefore, the signal of the $\mathrm{MH}^{+}+1$ isotope at $\mathrm{m} / \mathrm{z}$ $181^{\circ}$ is $^{\circ}$ shown ${ }^{\circ}$ in $^{\circ}$ Figure $^{\circ} 6 \mathrm{~b}$, to $^{\circ}$ present $^{\circ} \mathrm{a}^{\circ}$ correct $^{\circ}$ relationship between sample ion abundance and solution flow rate.

\section{Temperature and Gases}

The effect of the temperature and gas flows was tested in the Sciex prototype source by measuring the intensity of $\mathrm{MH}^{+}$of acridine in acetonitrile with different solvent and dopant flow rates, vaporizer temperatures, and gas flow rates. For the highest solvent flow rates, the optimum temperatures and gas flow rates were indeed higher than for the lower solvent flow rates, which indicates that more heat and more powerful nebulization is needed at higher solvent flow rates. However, even with the highest possible temperature $\left(500^{\circ} \mathrm{C}\right)$ and gas flows, the analyte signal was observed to level off at high flow rates. Therefore, the apparent ion loss cannot be explained by insufficient nebulization and evaporation.

\section{Amount of Photons}

To investigate whether the output of photons from the lamp is insufficient for the efficient ionization of the dopant and other species, acridine was analyzed in acetonitrile, again by changing the flow rate and this time also the lamp current of the Sciex prototype source. The lowest lamp current used was $0.42 \mathrm{~mA}$, the highest was $1.92 \mathrm{~mA}$, instead of the normally used $0.78 \mathrm{~mA}$. The signal of $\mathrm{MH}^{+}$of acridine was slightly more intense with the higher lamp current, but the trend was still identical to that obtained with the lower lamp currents: the signal saturated at higher flow rates. The conclusion is, therefore, made that saturation of the ion signals is not due to insufficient emission of photons from the lamp.

The photons may also be lost through absorption by solvent ${ }^{\circ}$ molecules ${ }^{\circ}$ at $^{\circ}$ higher $^{\circ}$ flow $^{\circ}$ rate $^{\circ}\left(\right.$ Scheme $^{\circ} 2,{ }^{\circ}$ Reaction 2). ${ }^{\circ}$ Cross $^{\circ}$ sections ${ }^{\circ}$ for ${ }^{\circ}$ absorption ${ }^{\circ} y^{\circ}$ acetonitrile ${ }^{\circ}$ and chloroform are given in Table 2 . Evaporation of $1 \mathrm{~mL}$ of acetonitrile or chloroform yields approximately $440 \mathrm{~mL}$ or $280 \mathrm{~mL}$ of solvent vapor at 1 atm and roomtemperature. Gas flows through the Sciex source are: lamp gas $1 \mathrm{~L} / \mathrm{min}$, nebulizer gas $2 \mathrm{~L} / \mathrm{min}$ (estimated), and auxiliary gas $3 \mathrm{~L} / \mathrm{min}$ (estimated), totaling 6 $\mathrm{L} / \mathrm{min}$. The fraction of acetonitrile vapor at $100 \mu \mathrm{L} / \mathrm{min}$ in the vapor-phase is $0.044 / 6$. Then, the number density of acetonitrile can be calculated as $2.10^{17}$ molecules/ $\mathrm{cm}^{3}$. For a layer of a mixture of nitrogen and acetonitrile the photon intensity that is transmitted is

$$
\frac{I}{I_{0}}=e^{-\sigma n x}
$$

where $\sigma$ is the photon absorption cross section, $\mathrm{n}$ is the number density of acetonitrile and $x(\mathrm{~cm})$ is the thickness of the layer of gas.

Using this equation for a $1 \mathrm{~mm}$ thick layer, we obtain $\mathrm{I} / \mathrm{I}_{0}=0.55$ at $100 \mu \mathrm{L} / \mathrm{min}, 0.30$ at $200 \mu \mathrm{L} / \mathrm{min}$, and 0.05 at $500 \mu \mathrm{L} / \mathrm{min}$. This calculation demonstrates that photon absorption is extremely strong at 500 and 1000 $\mu \mathrm{L} / \mathrm{min}$. Similar numbers can be calculated for chloroform. The calculation suggests that dopant ions can be generated in a layer close to the lamp window, and that photons cannot penetrate several millimeters into the ionization region at flow rates above $200 \mu \mathrm{L} / \mathrm{min}$.

This was tested by delivering the dopant to the Sciex prototype source together with the lamp gas and not with ${ }^{\circ}$ the ${ }^{\circ}$ auxiliary ${ }^{\circ}$ as $^{\circ}$ as $^{\circ}$ usual (Figure ${ }^{\circ} 1$ ). ${ }^{\circ}$ The $^{\circ}$ aim $^{\circ}$ was to have more efficient ionization of the dopant, as the

Table 2. VUV $^{\circ}$ Photon ${ }^{\circ}$ absorption ${ }^{\circ}$ of $^{\circ}$ solvents $^{\circ}[27,28]$

\begin{tabular}{lc}
\hline Solvent & $\begin{array}{c}\text { Cross section for photon absorption } \\
\text { at } 10.0 \mathrm{eV}(123 \mathrm{~nm})\end{array}$ \\
\hline \hline Acetonitrile & $30.10^{-18} \mathrm{~cm}^{2}$ \\
Chloroform & $35.10^{-18} \mathrm{~cm}^{2}$ \\
\hline
\end{tabular}


dopant molecules would meet the photons in front of the lamp window before absorption by the solvent could take place. The new configuration as well as two different lamp gas flows (1-41/min) were tested during the analysis of acridine in acetonitrile, but no significant differences could be found in the saturation of the $\mathrm{MH}^{+}$ signal of acridine when compared with the situation where the dopant was delivered the usual way. It may be concluded that either the loss of photons in nonionizing interaction with solvent molecules is not important (which would contradict our calculation) or that the mixing of solvent vapor with lamp gas is such an efficient process that a clean sheath of dopant in lamp gas just in front of the lamp window cannot be established and absorption of photons by solvent vapor cannot be avoided. As a final consideration concerning photon absorption, it is difficult to explain why loss of photons leads to a much more pronounced loss of sensitivity for sample ionization by charge exchange than by proton transfer.

\section{Conclusions}

The total ion current (TIC), which consists mainly of dopant radical cations and other reactant ions, was observed to decrease at high solvent flow rates, as demonstrated by measuring the curtain plate and end plate currents of the two APPI sources. The signal of analyte radical cations $\left(\mathrm{M}^{+}\right)$was observed to decrease simultaneously with the dopant radical cations $\left(\mathrm{D}^{+\cdot}\right)$ and the TIC, whereas the signal of protonated analytes $\left(\mathrm{MH}^{+}\right)$was affected to a very minor extent. The decrease in the $\mathrm{M}^{+\cdot}$ of analytes is explained by neutralization of the $\mathrm{D}^{+}$, which inhibits the formation of $\mathrm{M}^{+\cdot}$ by charge exchange. For the formation of $\mathrm{MH}^{+}$through proton transfer, a sufficient amount of proton donors is present in the system despite the decreased amount of $\mathrm{D}^{+*}$, and therefore the proton transfer is not as seriously affected by the high solvent flow rate. With the Agilent/Syagen APPI source the $\mathrm{MH}^{+}$ions were efficiently formed even without the dopant, whereas the formation of $\mathrm{M}^{+\cdot}$ required the use of dopant with both ion sources. This and the high dependence of $\mathrm{M}^{+\cdot}$ signal on the flow rate suggest that the main route for the formation of $\mathrm{M}^{+\cdot}$ is charge exchange with the $\mathrm{D}^{+\cdot}$ and not direct photoionization. A simple calculation demonstrates that absorption of photons by solvent vapor may be a major contribution to the decreased output of ions from the APPI sources. However, absorption of photons cannot explain why loss of sensitivity is strong in the case of charge exchange, and very limited in the case of proton transfer.

Future experiments that may shed light on the mechanisms responsible for the observed flow rate dependence of the APPI source are extensive variations of all gas flows involved, to vary residence times of charge carriers, and thus vary the extent of ion-ion and ionelectron recombination. Measurement of VUV light attenuation as a function of solvent flow rate in the absence of dopant and sample may present a direct proof of the extent of VUV photon absorption.

\section{Acknowledgments}

The authors gratefully acknowledge financial support for this study by the Research Foundation of the University of Helsinki, Finnish Mass Spectrometry Society, Finnish Cultural Foundation, Finnish National Technology Center, Orion Pharma, Juvantia Pharma Ltd., and United Laboratories Ltd. The API 365 mass spectrometer and financial support for the construction of the prototype APPI source were provided by Applied Biosystems/ MDS Sciex. The Agilent/Syagen APPI source was a generous loan from Agilent Technologies.

\section{References}

1. Robb, D. B.; Covey, T. R.; Bruins, A. P. Atmospheric Pressure Photoionization: An Ionization Method for Liquid Chromatography-Mass Spectrometry. Anal. Chem. 2000, 72, 3653-3659.

2. Syage, J. A.; Evans, M. D.; Hanold, K. A. Photoionization Mass Spectrometry. Am. Lab. 2000, 32, 24-29.

3. Kauppila, T. J.; Kuuranne, T.; Meurer, E. C.; Eberlin, M. N.; Kotiaho, T.; Kostiainen, R. Atmospheric Pressure Photoionization. The Ionization Mechanism and the Effect of the Solvent on Ionization of Naphthalenes. Anal. Chem. 2002, 74, 54705479 .

4. Koster, G.; Bruins, A. P. Mechanisms for Ion Formation in LC/MS by Atmospheric Pressure Photo-Ionization (APPI).Proceedings of the 49th ASMS Conference on Mass Spectrometry and Allied Topics; Chicago, IL, May, 2001.

5. Kauppila, T. J.; Kotiaho, T.; Bruins, A. P.; Kostiainen, R. Negative Ion Atmospheric Pressure Photoionization. J. Am. Soc. Mass Spectrom. 2004, 15(2), 203-211.

6. Basso, E.; Marotta, E.; Seraglia, R.; Tubaro, M.; Traldi, P. On the Formation of Negative Ions in Atmospheric Pressure Photoionization Conditions. J. Mass Spectrom. 2003, 38, 11131115.

7. Rauha, J.-P.; Vuorela, H.; Kostiainen, R. Effect of Eluent on the Ionization Efficiency of Flavonoids by Ionspray, Atmospheric Pressure Chemical Ionization, and Atmospheric Pressure Photoionization Mass Spectrometry. J. Mass Spectrom. 2001, 36, $1269-1280$.

8. Leinonen, A.; Kuuranne, T.; Kostiainen, R. Liquid Chromatography-Mass Spectrometry in Anabolic Steroid Analysis-Optimization and Comparison of Three Ionization Techniques: ESI, APCI, and APPI. J. Mass Spectrom. 2002, 37, 693-698.

9. Keski-Hynnilä, H.; Kurkela, M.; Elovaara, E.; Antonio, L.; Magdalou, J.; Luukkanen, L.; Taskinen, J.; Kostiainen, R. Comparison of Electrospray, Atmospheric Pressure Chemical Ionization and Atmospheric Pressure Photoionization in the Identification of Apomorphine, Dobutamide, and Entacapone Phase II Metabolites in Biological Samples. Anal. Chem. 2002, 74, 3449-3457.

10. Yang, C.; Henion, J. Atmospheric Pressure Photoionization Liquid Chromatography-Mass Spectrometric Determination of Idoxifene and Its Metabolites in Human Plasma. J. Chromatogr. A 2002, 970, 155-165.

11. Hsieh, Y.; Merkle, K.; Wang, G.; Brisson, J.-M.; Korfmacher, W. A. High-Performance Liquid Chromatography-Atmospheric Pressure Photoionization/Tandem Mass Spectrometric Analysis for Small Molecules in Plasma. Anal. Chem. 2003, 75, 3122-3127.

12. Hsieh, Y.; Merkle, K.; Wang, G. Zirconia-Based Column HighPerformance Liquid Chromatography/Atmospheric Pressure Photoionization Tandem Mass Spectrometric Analyses of 
Drug Molecules in Rat Plasma. Rapid Commun. Mass Spectrom. 2003, 17, 1775-1780.

13. Hakala, K. S.; Luukkanen, L.; Kaukonen, A. M.; Hirvonen, J.; Kostiainen, R.; Kotiaho, T. Development of LC/MS/MS Methods for Cocktail Dosed Caco-2 Samples Using Atmospheric Pressure Photoionization and Electrospray Ionization. Anal. Chem. 2003, 75, 5969-5977.

14. Kauppila, T. J.; Kostiainen, R.; Bruins, A. P. Anisole, a New Dopant for Atmospheric Pressure Photoionization-Mass Spectrometry of Low Proton Affinity, Low Ionization Energy Compounds. Rapid Commun. Mass Spectrom. 2004, 18, 808-815.

15. Kertesz, V.; Van Berkel, G. J. Surface-Assisted Reduction of Aniline Oigomers, n-Phenyl-1,4-Phenylenediimine and Thionine in Atmospheric Pressure Chemical Ionization and Atmospheric Pressure Photoionization. J. Am. Soc. Mass Spectrom. 2002, 13, 109-117.

16. Takino, M.; Daishima, S.; Nakahara, T. Determination of Perfluorooctane Sulfonate in River Water by Liquid Chromatography Mass Spectrometry by Automated On-Line Extraction Using Turbulent Flow Chromatography. Rapid Commun. Mass Spectrom. 2003, 17, 383-390.

17. Yoshiyoka, N.; Akiyama, Y.; Teranishi, K. Rapid Simultaneous Determination of O-Phenylphenol, Diphenyl, Thiabendazole, Imazalil, and Its Major Metabolite in Citrus Fruits by Liquid Chromatography-Mass Spectrometry Using Atmospheric Pressure Photoionization. J. Chromatogr. A 2004, 1022, 145-150.

18. Marotta, E.; Seraglia, R.; Fabris, F.; Traldi, P. Atmospheric Pressure Photoionization Mechanisms 1. The Case of Acetonitrile. Int. J. Mass Spectrom. 2003, 228, 841-849.

19. Takino, M.; Daishima, S.; Nakahara, T. Determination of Chloramphenicol Residues in Fish Meats by Liquid Chromatography-Atmospheric Pressure Photoionization Mass Spectrometry. J. Chromatogr. A 2003, 1011, 67-75.
20. Delobel, A.; Halgand, F.; Laffranchise-Gosse, B.; Snijders, H.; Laprévote, O. Characterization of Hydrophobic Peptides by Atmospheric Pressure Photoionization-Mass Spectrometry and Tandem Mass Spectrometry. Anal. Chem. 2003, 75, 59615968.

21. Takino, M.; Daishima, S.; Nakahara, T. Liquid Chromatography/Mass Spectrometric Determination of Patulin in Apple Juice Using Atmospheric Pressure Photoionization. Rapid Commun. Mass Spectrom. 2003, 17, 1965-1972.

22. Robb, D. B.; Covey, T. R.; Bruins, A. P. Atmospheric Pressure Photoionization: A New Ionization Technique For LC/MS. Proceedings of the 48th ASMS Conference on Mass Spectrometry and Allied Topics; Long Beach, CA, June, 2000.

23. Hanold, K. A.; Fischer, S. M.; Cormia, P. H.; Miller, C. E.; Syage, J. A. Atmospheric Pressure Photoionization. 1. General Properties for LC/MS. Anal. Chem. 2004, 76, 2842-2851.

24. Covey, T. R.; Lee, E. D.; Bruins, A. P.; Henion, J. D. Liquid Chromatography/Mass Spectrometry. Anal. Chem. 1986, 58, 1451A-1461A.

25. Syage, J. A. Mechanism of $[\mathrm{M}+\mathrm{H}]^{+}$Formation in Photoionization Mass Spectrometry. J. Am. Soc. Mass Spectrom. 2004, 15, 1521-1533.

26. Linstrom, P. J.; Mallard, W. G., Eds.; NIST Chemistry WebBook, http://webbook.nist.gov

27. Eden, S.; Limao-Vieira, P.; Kendall, P.; Mason, N. J.; Hoffmann, S. V.; Spyrou, S. M.High Resolution Photo-Absorption Studies of Acrylonitrile, $\mathrm{C}_{2} \mathrm{H}_{3} \mathrm{CN}$, and Acetonitrile, $\mathrm{CH}_{3} \mathrm{CN}$. Eur. Phys. J. Atom. Mol. Opt. Phys.2003, 26, 201-210.

28. Vatsa, R. K.; Volpp, H.-R. Absorption Cross-Sections for Some Atmospherically Important Molecules at the H Atom Lyman- $\alpha$ Wavelength (121.567 nm). Chem. Phys. Lett. 2001, 340, 289-295. 